\title{
Matoš i postmoderna, A.G.M. kao matrix hrvatske književnosti
}

\begin{abstract}
Rem Goran, Matoš i postmoderna, A.G.M. kao matrix hrvatske književnosti (Antun Gustav Matoš and Croatian Postmodernism). „Poznańskie Studia Slawistyczne” 7. Poznań 2014. Publishing House Science and Innovate. pp. 197-210. ISBN 978-83-63795-79-5. ISSN 2084-3011.

The article Matoš and Croatian Postmodernism shows that it was Boro Pavlović (1921-2001), the anticipator and ,the father" of Croatian postmodernism, the author of fifty collections of poems and numerous media creations of Walter Benjamin's provenance in the 50's (exhibition of poems We in 1942, collection News in 1954, the project-exhibition Encyclopedia poetica in 1957/1958, and computer poem MOrpheus in 1978), who figuratively, impressively, but accurately summed up the importance of the impressionist, symbolist and Art Nouveau author A.G.M. for the overall Croatian literature.
\end{abstract}

Keywords: postmodernism; expressionism; dadaism, surrealism; futurism; constructivism; existentialism

\section{Uvod u polemičnog Učitelja}

Rad Matoš i postmoderna, A.G.M. kao matrix hrvatske književnosti istraživački će se kretati u trima smjerovima: istražit će utjecaj književne i kritičarsko-esejističke poetike Antuna Gustava Matoša na postmoderne književnoznanstvene poetike, na postmoderne književne poetike te će provjeriti postmodernu osjetljivost ${ }^{1}$ Matoševa pisma, odnosno primjenjivost

1 Sintagma postmoderna osjetljivost rabi se kao značenjska analogija sintagmi intermedijalna osjetljivost (Rem 2011: 63) koja imenuje intermedijalno strukturirana pjesnička pisma što su nastajala prije teorijske elaboracije pojma intermedijalnost. Dakle, sintagmom se postmoderna osjetljivost ovdje označava postojanje postmodernih elemenata u pismu koje je nastalo prije postmodernog perioda, odnosno prije utvrđivanja teorijskih značajki postmoderne. 
recentnih svjetskih postmodernih kulturalnih i teorija identiteta na Matošev tekst. Drugim riječima, fokusirajući se na temeljni pojam komparativnog istraživanja (Weisstein 1968: 88) - pojam utjecaja - rad će se primarno baviti prostorom recepcije, i to ,produktivne recepcije” (Beker prema Moog-Grünewald 1995: 44), dok će se reference na pošiljaoca - na tekst A.G. Matoša - analizirati u tom kontekstu:

- kao argumentacijski materijal teze o postojanju sustavne produktivne znanstvene i književne projekcije Matoševe ukupne poetike - u postmoderni, ali i

- kao pokazatelj kontinuiteta takvog intertekstuiranja, s obzirom na Matošev tekst kao prostor produktivne recepcije njemu tradicijskih autora.

U tako naznačenome, ali i u kontekstu istraživanja postmoderne osjetljivosti Matoševa pisma, kao paradigmatski će se referirati njegov esejski-putopisni tekst Iz Samobora (Matoš 1994: 70-82) te u manjem broju primjera pjesme Utjeha kose, Jesenje veče i Notturno.

Značenje impresionističkog, simbolističkog i secesijskog književnika A.G.M.-a za hrvatsku ukupnu književnost figurativno je, impresijski, ali precizno, još pedesetih godina sažeo Boro Pavlović (1921.-2001.), anticipator i začetnik hrvatske postmoderne, autor pedesetak zbirki pjesama te niza medijskih radova walterbenjaminovske provenijencije (izložba pjesama $\mathrm{Mi}$ iz 1942., zbirka Novina iz 1954. i izložba-projekt Enciklopedija poetika iz 1957./8. pa kompjutorska poema Morfej iz 1978.). On ukazuje na Matoševa brojna i eksplicitna intertekstuiranja hrvatske književne baštine, na potezu od humanističkog Marka Marulića (1450.-1524.) pa do baroknog Ivana Gundulića (1589.-1638.) te prosvjetiteljskog Matije Antuna Reljkovića (1732.-1798.) i romantičnog Ivana Mažuranića (1814.-1890.), a svakako i realističkog Ksavera Šandora Gjalskog (1854.-1935.). Potom ukazuje na A.G.M.-ov jak trag u pismima autora koji slijede iza njega: u ekspresionističko-egzistencijalističkom i soc-art pismu Miroslava Krleže (1893.-1981.) te u egzistencijalističko-apsurdističkom tekstu Ranka Marinkovića (1913.-2001.). Ta svijest o Matoševu mjestu, kao očito jak metatekstem, aktivirala je i brojne književnoznanstvenike (Ivo Frangeš [1920.-2003.], Aleksandar Flaker [1924.-2010.] te Miroslav Šicel [1926.-2011.]) da fokusiraju neke svoje ključne teorijsko-povjesničarske teze, a samog Pavlovića ponukala ne samo da napiše poemu te dramu A.G.M., nego i da zaključi u svom tekstu 
iz 1954.: „Što je Matoš drugo nego Hrvatska?” (Pavlović 2005: 20). Matošev tekst Iz Samobora, i kao esej i kao putopis, ovjerava da je Matoš takva, kumulativno-recepcijska, hiperosjetljiva tekstualna matrica, napeta od gomilanja i rastvaranja.

Nakon postmodernog začinjavca Pavlovića (inače višekratno imenovana kao nastavljača Tina Ujevića [1891.-1955.], a taj je, Veliki Tin, postao najrazvijeniji hrvatski pjesnički multipoetik XX. stoljeća [kod njega su odčitani: neosimbolizam, ekspresionizam, dadaizam, nadrealizam, futurizam, konstruktivizam, egzistencijalizam], znamo, bio u ozbiljnoj polemici sa svojim Učiteljem - upravo A.G.M.-om!!!) citatno se Matošu obraćaju i mlađi postmodernisti: Milorad Stojević ludistično sedamdesetih, Anka Žagar bajkovito osamdesetih, palindromatski Dubravka Oraić Tolić osamdesetih i devedesetih te post-non-propedeutički ili neokabaretski - autori početka trećeg milenija (npr. Marinko Plazibat).

\section{A.G.M.-ov trag u strateškom književnopovijesnom umu hrvatske književnosti 20. stoljeća}

Kako se već naznačilo, ovaj će rad u cijelosti, potpunim slijedom i označavanjem punog opsega predmetnog eseja-putopisa, nastojati biti prenositeljem značenjskih reprojekcija Matoševa teksta Iz Samobora (Matoš 1994: 70-82), koji s jedne strane svojom poližanrovskom strukturom generira strateški književnopovijesni um hrvatske književnosti 20. stoljeća, a s druge se pokazuje anticipacijskim u smislu afirmiranja danas relevantnih postmodernih teorija identiteta, književnosti i kulture.

Strateški je književnopovijesni um hrvatske književnosti 20. stoljeća, generiran Matoševim tekstom, moguće osvijetliti preko strategija pristupa tekstu Iz Samobora četiriju hrvatskih književnih znanstvenika - Bore Pavlovića, Miroslava Šicela, Ive Frangeša i Dubravke Oraić Tolić.

Kao uvidno polazište, referirati je sintetičnu tvrdnju anticipatora i sudionika, odnosno roditelja hrvatske postmoderne B. Pavlovića ${ }^{2}$. Pavlović je,

2 Boro Pavlović, 27. travnja 1922. (Slavonska Požega) - 7. rujna 2002. (Duga Resa), autor pedesetak zbirki pjesama, od kojih je prva Dobro jutro iz 1943., konstruktivist i pripadnik, kako to bilježi Aleksandar Flaker, ,ine inačice hrvatske avangarde” (Flaker 1988: 251-259). 
naime, uz četrdesetogodišnjicu smrti A.G.M.-a napisao: „Matoš nije hrvatski književnik nego hrvatska književnost"3.

Pristupe Miroslava Šicela i Dubravke Oraić Tolić Matoševu tekstu može se čitati kao konstruktivnu polemiku (bez njihova osvješćivanja takve mogućnosti interpretacije odnosa njihovih teorija) koja je iznjedrila dva različita smjera teorijske elaboracije žanrovskih značajki uopće. Naime, Matošev je tekst, naslovljen Iz Samobora, moguće iz različitih teorijskih uvidnih kutova čitati: esejom (Šicel 2002) i putopisom (Oraić Tolić 1994). Toj dvostrukosti prići je uvidom u njegovu strukturnu osjetljivost koja implicira veliki broj ulazaka u taj tekst i još veći broj izlazaka iz njega. Zato se, tako skoro doktrinarno uzevši, navedeni tekst kao esej, ali i kao putopis, može strukturno osvijetliti: a) stanjem njegova subjekta koji zaneseno diskurzivira te ekologizira i kultivira tekstnost hrvatskog pejzaža, a pritom presudno i u slijedu putopisnoga romantičarskog barthesovca ${ }^{4}$ Antuna Nemčića (Edde, Mađarska, 14. siječnja 1813. - Križevci, 5. rujna 1849.) odbija biti reprezentantom ikakva zbiljskoipovijesnog autora, potom b) njegovom studijom stila, koji kumulativno raste u ostale tekstualne strukture, ali i unatražne i unaprijedne intertekstne emisije, c) temom, koja se svesrdno zamjenjuje s d) formom, odnosno semantizira se kult forme koji se realizira od vlastitoga označiteljskog nadrastanja nad, iako je eksplicitno i neupitno poliperspektivno razvijeno, označeno. Naime, iz provjere tih strukturnih realizacija Matoševa eseja-putopisa, M. Šicel, najzastupljeniji hrvatski povjesničar književnosti u drugoj polovici prošlog stoljeća, pa i prošlog tisućljeća, tzv. školski povjesničar hrvatske književnosti, 2002., dakle, već u novom

Smatra se poetološkim nasljednikom najznačajnijega hrvatskog pjesnika dvadesetog stoljeća T. Ujevića - koji je, pak, smatran učenikom A.G. Matoša, a sâm je s Matošem imao razdoblja i suglasja i bučnog razlaza. Napisao je u svojevrsnom lightverseu i objavio u samizdatu, karakteristično 1954. godine, i poemu a.g.m. koja stilizira Matošev život, a reaktualizacijski je pretiskana osamdesetih u krunskom hrvatskom postmodernom časopisu „Quorum” iz njegove projektne faze (Pavlović 1987: 305-315).

3 Uz četrdesetogodišnjicu Matoševe smrti, dakle 1954., B. Pavlović piše u „Zadarskoj reviji” esej Raskrsnica - Matoš i pita se figurom tvrdnje-odgovora: ,Jer konačno, što je Matoš?" (Pavlović 2005: 20).

${ }^{4}$ Goran Pavošević, priređujući za Croaticu putopise A. Nemčića pronalazi unutar tekstne odbijenice subjektova nepristajanja na reprezentiranje i dokumentiranje svojeg autora i naziva to ne samo prekoračenjem modernosti, nego i tekstualizmom, implicirajući - ne samo „protosmrt autora”, nego i neupitno „užiće u tekstu” (Pavošević 1998: 7-11). 
tisućljeću, bjelodani Antologiju hrvatskog književnog eseja XX. stoljeća i u prvom tomu te Antologije izbor, nimalo slučajno, započinje tekstom $I z$ Samobora (Šicel 2002: 39-48). Kroz ranije svoje književnopovjesničarske tekstove Šicel zagovara Matošev „kozmopolitski karakter simbolističkog značenja" (Šicel 1982: 135), koji se ulijeva u spomenute tekstualne strukture, a Solar, primjerice, o Utjehi kose napominje kako je ,uzor pjesnicima soneta" (Solar 1981: 103), što prethodno oprimjeruje kroz paradigmatski uzornu Matoševu mikrostrukturnu razvijenost (1981: 62, 63, 71, 93).

Referencom na Matoševu subjektivitetnu strukturu, Ivo je Frangeš postavio teorijski temelj razgraničavanja tekstualnog i autorskog subjekta, argumentirano akcentuirajući odmak od pozitivističkog čitanja književnog teksta (što će, tu subjektivitetnu strukturu, u njenom neposrednom tekstnom funkcioniranju, početkom 90-ih godina 20. stoljeća, kompleksnije razraditi Josip Užarević, 1991). Tako za oblikovanje subjektnog stanja u Matoševu hitu Jesenje veče, implicirajući relaciju subjektivitetna struktura - tematskomotivska struktura, Frangeš pripremno kaže: „ne smijemo zaboraviti jednostavnu istinu prema kojoj prizor u prirodi, sam za sebe, u «originalu», nema ni pozitivnog ni negativnog, ni patetičnog ni moralnog značenja, jer je priroda naprosto ravnodušna, bešćutna" (Frangeš 1980: 300).

Odmah je na početku trećeg tisućljeća, odmah i već, vrsna/žanrovska pomiješanost na djelu, naime naslov je Iz Samobora u više fokusnih pristupa D. Oraić Tolić opisan i određen putopisom, ali Šicelu je potreban, iz esejološkog kuta gledanja, za ilustrirati kako „Matoš svoju esejistiku tvori življom, «literarnijom», obogaćujući i prožimljući je i elementima drugih žanrova: u širokom rasponu od polemičkog feljtona preko naglašeno poetskih zaleta, do putopisnih razglednica i kalambura" (Šicel 2002: 12). Šicel, dakle, pomalo impresijski, ali jasno, uočava kompozicijsku ili žanrovsku diskompaktnost, kao međutim mogućnost reljefne te stoga polipercepcijske tekstualne osjetljivosti koja će reperkusije imati, kako je već najavljeno, u postmodernoj recepciji Matoševa teksta.

Može se sintezno reći kako književnoznanstvena pisma na (i u) relaciji Pavlović-Šicel-Frangeš-Oraić Tolić pokazuju da su književne strategije A.G. Matoša bile ishodišne i instruktivne za uspostavljanje hrvatskih modernističkih, odnosno postmodernih književnoznanstvenih strategija ${ }^{5}$.

${ }^{5}$ Ovaj četveroniz književnih znanstvenika nije potpun bez A. Flakera koji Matoša pozicionira kao poveznicu različitih književnopovijesnih škola kojih su nositelji I. Frangeš 


\section{Antinomija, simbolički poredak i neizbor lokalno-globalno}

S obzirom na takvu žanrovski hibridnu konstituciju Matoševa teksta, on je, kako se napomenulo, izrazito podatan za analitičko-interpretacijsku inskripciju postmodernih teorija, ne nužno nacionalne provenijencije, što će se vidjeti u nastavku postavljanjem Matoševa eseja-putopisa spram recentnih kulturalnih teorija čija se primjenjivost u Matoševu tekstu dodatno konkretizira figurom antinomije.

U prvoj kartici teksta, toga eseja-putopisa, čiji je naslov Iz Samobora, slika krajolika izravno locusno imenuje nekoliko zemljopisnih i kultiviranih arhiteksturnih punktova, a postavljen je i povijesni slijed hrvatske književnosti - od prvog imenitelja hrvatskoga tekstualnog subjekta Marka Marulića pa do moderne hrvatske književne slike devetnaestog stoljeća: Stanko Vraz, August Šenoa, Ante Kovačić i Ksaver Šandor Gjalski. Nije Matoš mogao znati, ali B. Pavlović jest, i prije i poslije teksta koji je napisao uz četrdesetogodišnjicu Matoševe smrti, da će šezdesetak godina kasnije Bogdan Mesinger napisati, snimajući jedan nešto istočnijehrvatski krajolik: ,ja znam jedan čudan kraj / gdje do rujna traje - maj” (Mesinger 1975: 79).

U zemlji slovinskoj

Grad se vidi jedan,

Kano grad od pčela

Krasan i uredan...

Jesen, prva hrvatska jesen iza dugog, dugog vremena...

Kao veče što nalikuje jutru, tako prva jesen liči blagoj mlačnosti svibnja. Septembar je zreli maj

(Iz Samobora, Matoš 1994: 70-71).

\footnotetext{
i A. Barac. Naime, osim što će Frangeš u studiji iz pedesetih (Frangeš 1980: 303), radno i u zagradi, otvoriti stilističku ,smrt autora”: „Ovdje valja odmah napomenuti da izrazi kao «Matoš je upotrijebio...», «Matoš je ostvario...» itd. imaju isključivo metaforičko značenje, i tako ih moramo shvatiti. Jer inače pjesma ne bi bila doživljaj, nego mučno, racionalno obrađivanje viđenoga i dogođenoga", takvi su Frangešovi redci, upozorava avangardolog i komparatist A. Flaker, obračun sa starom produljeno pozitivističkom književnopovjesničarskom školom A. Barca, školom kojoj su pedesete dale zamjenu u ,metodi unutrašnjeg pristupa” i stoga „nastojanju «s Vidrićem biti Vidrić, s Matošem Matoš»” (Frangeš 1980: 22).
} 
Vodeći hrvatski lirolog Josip Užarević, više kao ilustracijski, ali i kao radni te nimalo usputni primjer za baviti se književnim antinomijama, piše: „Kada npr. za Matoša kažemo da je bio dosljedan jedino u svojoj nedosljednosti - možda nam i ne pada na pamet da je i to semantička antinomija" (Užarević 2012: 193). Povijesnu fiziku zemljopisa i njegove morfološke ili sociološke sekcije i razlikovanja, Matošev je tekst zamijenio za fiziku pisma humanističke fikcijske refleksije, subjekt je stoga pismo koje ponavlja jezične strukture prostornih razmjerja $o d-d o, o d-$ preko - do i pritom konstituira i semantizira stanje meditacijske sinteze:

Krasan je Samobor. Blizina sa glavnim gradom daje mu čar blizog ladanja kao Tiburu, Tivoliju, Versaillesu, Saint-Cloudu, Schoenbrunnu, Windsoru. Okolica je srećna kombinacija od gore i ravnice, polja i šume, vrta i prirode, rijeke i planine, sela i zaseoka, grada i ladanja. - Krenite uz potok kroz brda kao kroz ogroman sjenast drvored, kao između ogromna dva zelena plota u starodrevno selo Rude i eto vas u klasičnoj planinskoj dolini, dok ste istodobno na istoku, na protivnoj strani za sat pješke u ribarskom, posavskom selu Otoku ili pod šimširima parka u divnim Gregorijančevim Mokricama nad slovenskom Savom. Kranjska, Štajer, uskočki Žumberak, Zagreb, Zagorje, jastrebarsko Prigorje, Susjed-grad, Lipovac, Okić, Mokrice, Slavetić, Jaska, Plješivica (Matoš 1994: 71).

Strategiju antinomijskog uspostavljanja identiteta prostora Matoš primjenjuje i u uspostavljanju identiteta subjekta u tom prostoru, odnosno identiteta prostora kao subjekta, pri čemu su komparacijski uvedena referentna mjesta presjecišta konkretnog i apstraktnog, neposrednog i posredovanog, stvarnog i fikcionalnog iskustva. Asocirati je ovdje također antinomijski postavljenu Lacanovu teoriju identiteta o kojoj Frederic Jameson upozorava:

Za Lacana, Simbolički Poredak je ono područje u koje dijete dospijeva, iz nekakve biološke bezimenosti, kada počinje postupno stjecati jezik. Područje je neosobno ili nadosobno, ali istovremeno omogućava nastanak osjećaja identiteta. Svijest, osobnost, subjekt prema tome su, kao što ćemo uskoro vidjeti, sekundarni fenomeni, koji su određeni širom strukturom samoga jezika ili Simboličkoga (Jameson 1978: 111).

\section{Matoš Lacanu ovako odgovara:}

Krajevi su ljudi, a ljudi su krajevi. „Predjeli su za mene bili uvijek ljudi” - veli Lamartine, ljubavnik Elvirin i elegijski pjesnik harmonijskog Jezera. Kao ljudi, nisu 
ni u Hrvatskoj svi okoliši jednako hrvatski. Ima kod nas okolica bez veće hrvatske duše, dok su neki naši pejzaži veliki Hrvati. Genius patriae super dormientibus filiis! (Matoš 1994: 72).

A Peter Kemper sintetizira: „Današnja bi pojednostavljena formulacija glasila: postmoderan je onaj kojega se kroz njegovu vlastitu nesigurnost više ne može učiniti nesigurnim" (Kemper 1993: 267). Nesigurnost ili neautoritarnost barem, stanja su koja se u romantizmu pripremaju zanosom, dovoljno nerealnim u ovisnosti o melankoliji da neupitno podupiru pripremu dolaska postmodernog stanja slabosti/malodušnosti, koje nastupa u dugosvirajućoj oprjeci s razotkrivenim zahtjevima amerikanizirane sreće i Oprah-vrištanja u publici (cf. Bruckner 2001: 208). Romantizam se postavljao bezironijski izravno tome suprotstavljen, odnosno kako Matoš veli:

To instinktivno osjećaju svi, osobito pjesnici, ljudi osjetljive duše. To je naročito u Samoboru osjećao Stanko Vraz. Samobor mu je kao simbol «slovinskog», hrvatskog idealnog mjesta, gdje je hrvatstvo kao kondenzovano i gdje je Hrvatska najhrvatskija. Ljepotu hrvatskog pejzaža, divotu primitivne duše hrvatske otkrio je on tu prvi od našh modernih pjesnika, ali ne svjesno, već logikom srca i simpatije (Matoš 1994: 73).

Iz perspektive teorije kulture, Matoševu je antinomiju čitati preko Eagletona koji piše:

Kako god bilo, nije riječ o izboru između toga da se bude građanin svijeta i član mjesne župe, samo zato što smo svako od toga s različitom svrhom i u različitim prilikama. I kultura kao uljuđenost i kultura kao identitet u tom su smislu dogmatske, jer tvrde da jedino može biti valjano sinoptičko viđenje, ili samo posebna prise de position (opredjeljenje) (Eagleton 2002: 63).

Antinomijsku sliku inferiornog i superiornog locusa te kulturne uljuđenosti s tim u vezi, Matoš donosi sljedećim redcima:

Kao da je tu kraj mene na istom mjestu, na samotnici klupi sušičavi poet, prvi hrvatski budnik i kritičar, otac balade i romance, licem sličan Alfredu de Mussetu, Ariostu i Šenoi, idealan, nesrećan i nepraktičan, stari boem u surci s elegancijom Boutet-de-Monvelovih melanholijskihdandyja, rođen ironik, govoreći o sve većem jazu između ljubavi i modernog života, pa o «ljudima od takozvanog praktičnog života, 
o ljudima koji imaju mjesto srca komadić govedine ili krmetine». Pa ipak, srce hrvatskog filistra bijaše u Vrazovo doba daleko bolje i plemenitije no danas. On je tako reći cijeli svoj vijek proživio u gostima, kao gost cijele Hrvatske (Matoš 1994: 74).

U svojim Američkim predavanjima osječki student jugoslavistike, tuzlanski profesor medijske kulture i književnosti Nedžad Ibrahimović, upravo Matoševom melankolijskom ironijom, piše:

U North Bendu sav svoj trud trošim na prepoznavanje toposa vremena kojega sam izgubio. Ovdje je, naprimjer, Laura pronađena mrtva, ovo je stara pilana, evo Dame S Cjepanicom, upravo je sjela za stol pokraj našega (...). Očekujem da se odnekuda pojavi i strašni Kepec ali njega nema (Ibrahimović 2011: 90).

Pita se zatim taj putopisni predavač što bi bilo kada bi se Cervantesovi, Don Quijoteovi, odnosno Goetheovi čitatelji, a u ovom je radu dopuniti pitanje s i Matoševi čitatelji, uputili za potragama koje bi na taj unatražni način prekoračivale mimezis pa semantizirale upitno mjesto na kojem se uopće nalazi ikoja topografija u međuprostoru čitatelja i fikcijske zbilje.

\section{Postmoderna love story, emocija, melankolija i bjelosvjetsko tržište}

Postmoderna melankolija kao emocija, paradoksalno razlabavljujuća po identitetnu homogenost svog pošiljatelja (manifestacijski signalizirana neodređenim ili množinskim zamjenicama), kontekstno, dakle, tipična u postmodernoj prozi i poeziji, prepoznatljiva je i u Matoševu eseju-putopisu te su čak i njena izvorišta usporediva.

Primjerice, dok jedan postmoderni lutalac svoju autoportretnu fikciju osvješćuje na putovanju neodređenim objektiviranim melankolijskim subjektnim likom: ,Zato se svaki sanjar koji se na tragu golubova ili starih ljubavi neprestano vraća na iste trgove, spotičući se uvijek iznova na istim starim ulicama i o iste pukotine u asfaltu, na kraju suočava s pitanjem, postavljenim samo njemu: selftest?" (Šteger 2010: 79), Matoš prividno kolektivnim, također melankolijski nastrojenim subjektom, replicira pukotinama u asfaltu ovakvom njihovom opet antinomijski postavljenom interpretacijom: 
Naša domovina preskupo plati divotu svog pejzaža. Hrvatska ne bi bila tako divna, da nije tako nesrećna, tako siromašna. Dok civilizacija u drugim naprednim zemljama, dok industrijalizam uništuje djevičanstvo prirode, obarajući šume, uništujući idilu sela i stvarajući velegradove koji žderu ladanje, naša zemlja je još vrlo primitivna, i naša priroda je još uvijek prirodna. Naši gradovi su još velika sela sa građanskim navikama (Matoš 1994: 77).

Civilizacijsko obilje kao izvor, paradoksalno rečeno, subjektove hektične melankolije, stanje je prepoznatljivo kako u postmodernom tekstu Branka Čegeca, tako i u (protopost)modernomesejskom-putopisnom Matoševu tekstu. Postavljajući se između diskurzivnosti i odumrlog diska, tekst se postmodernog B. Čegeca, citatno uskličan kao tekstovi Branka Maleša iz Prakse laži (Maleš 1986), podsjeća da je svijet objavljen i umnožen u medijima koji tranzitiraju pojedinca u bjelosvjetsko tržište:

mitovi su u prošlosti, budućnost je u mitovima i korupciji! subotom, djevojke se postrojavaju ispred crazybulla omotane u magnetni celofan: tko prođe zalijepi se! a prolaze lica s naslovnica.

moraš imati barem novine po mjeri! za jutro, za večer i za svaki od dvadeset i četiri sata!

(Kratka povijest tranzicije, Čegec 2010: 67).

Tom povoljnom i jeftinom, zabavnom te postmodernom svijetu priprema je bila Matoševa subjektna struktura misterijske nejasnoće:

Čita, sanja o republici u Rimu, o Rienziju i o zlatu Laurine kose, nezadovoljan kao pravi romantik sa savremenošću čezne za Atenom i Rimom, zanosi se za starim rukopisima, flauta i gitara razblažuju i razdražuju ga do ludila, penje se na brijeg Ventoux i tu zaključuje da je misterij ljudske duše ogromniji i dublji od zagonetke svih vidljivosti (Matoš 1994: 79).

O toposnoj temi lirike - love story - Walter Benjamin promišlja kako uz interese nadrealizma vidjeti nemimetičan puzzle složen kroz fraktale:

Dama je u ezoteričnoj ljubavi najmanje bitna. Tako je i kod Bretona. On je bliži stvarima kojima je bliska Nađa nego njoj samoj. Pa koje su to stvari kojima je ona bliska? Kanon tih stvari je za nadrealizam maksimalno poučan. Gdje početi? On se 
može pohvaliti zapanjujućim otkrićem. On je prvi naišao na revolucionarne energije koje se pojavljuju u ,zastarelom”, u prvim gvozdenim konstrukcijama, prvim fabričkim zgradama, najranijim fotografijama, predmetima koji počinju da odumiru, salonskim klavirima, haljinama od pre pet godina, mondenskim lokalima kad moda počinje da se iz njih povlači. Niko ne može preciznije od ovih pisaca znati kako te stvari stoje u odnosu na revoluciju (Benjamin 1974: 262-263).

Tu se donekle, ali jasnije ne može, vidi i neočekivani načelni aktivizam modernističke lirike, koji se neupitno nastoji čistiti od nadrikulture, ako je se osvijetli kao sediment urbanih taloga i modernog porobljavanja. Benjamina to zanima kao osvjetljavanje njihova, nadrealističkih pisaca, uspostavljanja pozicije revolucionarnog nihilizma, kao najintimnijega mogućeg krajolika, no ne i u Matoševu smjeru pejzažne transpovijesne ekologije, ali je taj slijed nužan i dijelom je precizne geste suprotstavljanja realističkoj oprjeci ruralno-urbano te postavljanja paralelnoga koordinativnog sustava razlike. Taj se obuhvatom odnosa osjetljivo dade projicirati na semantičko platno Matoševa određivanja strukture prostornih razmjerja od-do, od-preko-do:

Ali Petrarca nije prvi pejzažista i romantik. Već prije njega osjeti neurastenična gradska duša — taedium vitae, acedia — čežnju za selom, za prirodom, za ladanjskim mirom i zdravljem. Teokrit je reakcija proti aleksandrijskoj, Vergilova i Horacijeva idila proti rimskoj velegradskoj hipercivilizaciji, i kada bi god ljudska duša oboljela u nadrikulturama, bolji dusi traže lijeka na selu, na njedrima prirode i primitivnosti poput Isukrsta, božanskog prijatelja djece, jezera i priprostih ljudi (Matoš 1994: 79).

\section{Smrt Učitelja}

Osim esejske-putopisne proze i Matošev je poetski tekst pogodan postmoderni prototekst te isti tekstualni prostor - prostor pjesme, provocira na uzvrat, posebno onaj dio koji osvješćuje Matošev aktivan odnos spram neknjiževnih medija, primjerice likovnosti, glazbe te spram tekstualnog ludusa. Tako 70-ih godina 20. stoljeća M. Stojević pjesmovno referira leksem fotos kao predmet prijepiske Jure Tkalčića i A.G. Matoša (Stojević 2000: 83), 80-ih Maja Gjerek cijelu pjesmu Antunov bijeg ozvukovljava leksemima tišine (Gjerek 1998: 74-75), 90-ih i 2000-ih Stjepan Blažetin šalje pjesmovnu posvetu Matošu sintA.G.M.atskim citatnim završetcima ,guta već 
daljina" (Blažetin 2009: 27), Božica Zoko lista lijeve i desne hrvatske mišice (Zoko 2007: 32), Vlasta Markasović u pjesmi Opaklija noći citatno nokturira (Markasović 2013: 25), a Marinko Plazibat pjesmom Vrbanjski toranj, notturno (Plazibat 1999: 35) ludusno palimpsestira Matošev Notturno.

Nonprosvjetiteljska citatna pouka u pjesmi Marinka Plazibata Vrbanjski toranj, notturno, obuhvaćena je recepcijski u studijskom i antologijsko-panoramskom stilističkom istraživanju naslovljenu Panonizam hrvatskoga pjesništva (Jukić, Rem 2012/2013: 324-325). Matoševa pjesma Notturno (1996: 89), inače uvrštavana u sve najreprezentativnije antologije hrvatskog pjesništva, kao i gimnazijske čitanke posljednjih i postmodernih četrdeset godina, u toj je Plazibatovoj pjesmi palimpsestirana i psihodelično demobilizirana od svoje prvotne sonetne napetosti, metričke perfekcije i slikovne sedimentne introspekcije te joj je postavljeno rastvoreno stanje skokovito kadrirane filmičnosti. Ta je pojačana svim malim početnim slovima i vedro-ludističnim ja-Učitelj subjektom, koji se tom zaigranošću i organskije približava svojim infantnim sukomunikatorima, ali i nostalgično „sezonski” umire, dakako prije kakvog A.G.M.-recepcijskog „reuniona” pa makar to bila i stopedesetgodišnjica rođenja. Evo i uvida u tu Plazibatovu intertekstnu strukturiranost: „vješta je mahovina sise u gluho doba. / noge već nespretno tuku zidove no toranj / božanskim projektom grbav i kos / ostaje za jednu krhku sezonu ljepote / dovoljno čvrst” (Plazibat 1999: 35).

\section{Poslije zaključka}

Zaključno je izložiti kako su se upravo kroz iščitavanja Matoša smjenjivale velike književnopovjesničarske i teorijske škole te paradigme, koje su međutim upravo, zrcalno gledano, sam morfološki lik i slijed poetika kroz ravno stotinu godina.

Matoš je: a) prikupljao svjetlosno-reflektivne tragove pisama iz kojih je isijavala svijest o pismu, tragove pisama koja su bila jaka i pisala hrvatske povijesno aktivne poetike. Zrcalno i projektivno iz takve recepcijske pribranosti, slijedi i b) prijelaz njegova pisma u sljedećih stotinu godina povijesno aktivnih poetika. Poseban, nimalo pobočni, nego ovjeravajući Matošev trag u povijestima hrvatske književnosti je činjenica da su se upravo, c) kroz 
pristupe Matošu razdvajale i smjenjivale, radikalno ispostavljale različitima, paradigme hrvatske povjesničarske i teorijske književne misli. Svijest o pismu se kroz čitanje Matoša strategemski objelodanjivala Razlikom. Ujevićev se međuratni avangardni esej odricao autorove biografije, Frangešova studija iz pedesetih isticala samo nužno metaforičnu nazočnost imenovanog autora $\mathrm{u}$ interpretatorovim izrazima, Flaker supotpisivao tu Frangešovu metodološku eksplikaciju, dok je Slamnig fokusirao načelnu nuždu komparatistike, a postmoderna ludusnu poetiku brisanih navodnika.

\section{Literatura}

Beker M., 1995, Uvod u komparativnu književnost, Zagreb.

Benjamin W., 1974, Eseji, prev. M. Tabaković, Beograd.

Blažetin S., 2009, Oproštaj, „Književna revija” br. 4, str. 27.

Bruckner P., 2001, Neprestana ushićenost, prev. A. Buljan, Zagreb.

Čegec B., 2010, Zapisi iz pustog jezika, Zagreb.

Eagleton T., 2002, Ideja kulture, prev. G.V. Popović, Zagreb.

Flaker A., 1988, Hrvatske inačice ine avangarde, u: Suvremeno hrvatsko pjesništtvo, ur. A. Stamać, Zagreb, str. 251-259.

Frangeš I., 1980, Izabrana djela, sv. 149, Pet stoljeća hrvatske književnosti, prir. A. Flaker, Zagreb.

Gjerek M., 1998, Posvećene pjesme, Zagreb.

Ibrahimović N., 2011, O poeziji, pticama i drugim varkama. Američka predavanja, Sarajevo.

Jameson F., 1978, U tamnici jezika, prev. A. Šoljan, Zagreb.

Jukić S., Rem G., 2012/2013, Panonizam hrvatskoga pjesništva I-II, Budimpešta-Osijek. Kemper P., 1993, Bijeg unaprijed ili pobjeda prisnoga?, u: Postmoderna ili Borba za budućnost, prir. P. Kemper, prev. D. Horvat, D. Pehar, G.D. Grozdanić, Zagreb, str. 257-270.

Maleš B., 1986, Praksa laži, Rijeka.

Markasović V., 2013, Sakrita rič, Osijek.

Matoš A.G., 1994, Putopisi, prir. D. Oraić Tolić, Vinkovci.

Matoš A.G., 1996, Notturno, u: idem, Izabrane pjesme, Zagreb, str. 89.

Mesinger B., 1975, Začarani neki kraj, u: Zaljubljenici Cibalae, prir. V. Rem, Vinkovci, str. 79.

Nemčić A., 1998, Putositnice, prir. G. Pavošević, Vinkovci.

Oraić Tolić D., 1994, Pogovor, u: A.G. Matoš, Putopisi, Vinkovci, str. 179-192. 
Pavlović B., 1954, Raskrsnica - Matoš, „Zadarska revija” br. 2, str. 104-106.

Pavlović B., 1987, A.G.M., „Quorum” br. 1-2, str. 305-315.

Pavlović B., 2005, Album vedrine, prir. J. Pandurić, G. Rem, Zagreb.

Pavošević, 1998, Predgovor, u: A. Nemčić, Putositnice, Vinkovici, str. 7-11.

Plazibat M., 1999, Postelja od orahove sjene, Drenovci.

Rem G., 1988, Poetika brisanih navodnika, Zagreb.

Rem G., 2011, Pogo i tekst, Zagreb.

Solar M., 1975, 1981, Teorija književnosti, Zagreb.

Stojević M., 2000, Vrapci... und Kameraden na Mornaričkom groblju u Puli (Oder: Die Rose in der Culturgeschichte), u: idem, Moj kućni mandarin, Zagreb, str. 83.

Šicel M., 1982, Hrvatska književnost, Zagreb.

Šicel M., 2002, Antologija hrvatskog književnog eseja XX. stoljeća, Zagreb.

Šteger A., 2010, Berlin, prev. E. Fičor, Zagreb.

Užarević J., 1991, Kompozicija lirske pjesme, Zagreb.

Užarević J., 2012, Književni minimalizam, Zagreb.

Weisstein U., 1968, Einfuhrung in die vergleichende Literaturwissenschaft, Stuttgart.

Zoko B., 2007, Ljeto, u: eadem, Crveno more, Zagreb, str. 32. 